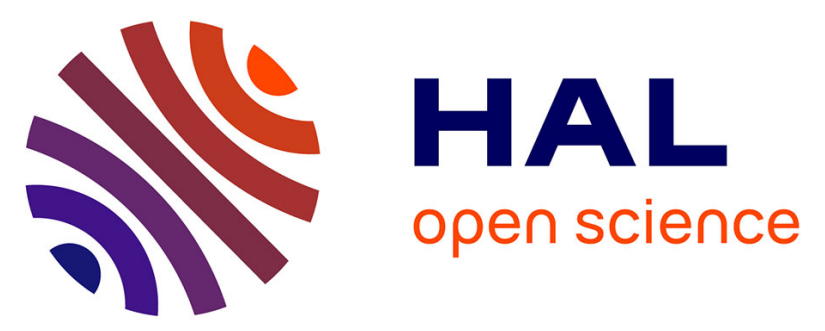

\title{
Missing the forest for the trees? A high rate of motor and language impairments in Disruptive Mood Dysregulation Disorder in a chart review of inpatient adolescents
}

Xavier Benarous, Cosmin Iancu, Jean-Marc Guilé, Angèle Consoli, David Cohen

\section{To cite this version:}

Xavier Benarous, Cosmin Iancu, Jean-Marc Guilé, Angèle Consoli, David Cohen. Missing the forest for the trees? A high rate of motor and language impairments in Disruptive Mood Dysregulation Disorder in a chart review of inpatient adolescents. European Child and Adolescent Psychiatry, 2021, 30 (10), pp.1579-1590. 10.1007/s00787-020-01636-y . hal-03462124

\section{HAL Id: hal-03462124 \\ https://hal.sorbonne-universite.fr/hal-03462124}

Submitted on 1 Dec 2021

HAL is a multi-disciplinary open access archive for the deposit and dissemination of scientific research documents, whether they are published or not. The documents may come from teaching and research institutions in France or abroad, or from public or private research centers.
L'archive ouverte pluridisciplinaire HAL, est destinée au dépôt et à la diffusion de documents scientifiques de niveau recherche, publiés ou non, émanant des établissements d'enseignement et de recherche français ou étrangers, des laboratoires publics ou privés. 
Missing the forest for the trees? A high rate of motor and language impairments in Disruptive Mood Dysregulation Disorder in a chart review of inpatient adolescents

Xavier Benarous ${ }^{1,2,3}$ xavierbenarous@gmail.com, Cosmin Iancu² $\underline{\text { cosmin.cristian.iancu@gmail.com, }}$ Jean-Marc Guilé1,3,4 guile.jean-marc@,chu-amiens.fr, Angèle Consoli ${ }^{2,5}$ angele.consoli@aphp.fr, David Cohen ${ }^{2,6} \underline{\text { david.cohen@psl.aphp.fr }}$

${ }^{1}$ Department of Child and Adolescent Psychopathology, Amiens University Hospital, Amiens, France

2 Department of Child and Adolescent Psychiatry, Pitié-Salpêtrière Hospital, Sorbonne University, Paris, France

3 INSERM U1105 Research Group for Analysis of the Multimodal Cerebral Function, University of Picardie- Jules Verne (UPJV), Amiens, France

${ }^{4}$ Department of Psychiatry, McGill University, Montreal, Canada

${ }^{5}$ Group of Clinical Research-15, Dimensional approach of child and adolescent psychotic episodes, Sorbonne University, Paris, France

${ }^{6}$ CNRS UMR 7222, Institute for Intelligent Systems and Robotics, Sorbonnes Université, Paris, France

Address of correspondence: Xavier Benarous, Department of Child and Adolescent Psychopathology, Amiens University Hospital. CHU Amiens-Picardie, Site Sud 80054 Amiens, France

Email : Benarous.xavier@,chu-amiens.fr

Phone : +33(0) 322087630

Fax : +33(0) 322082331

Category: Original contribution

Abbreviated title: Developmental impairments in DMDD

Conflict of interest: On behalf of all authors, the corresponding author states that there is no conflict of interest.

Acknowledgment: I thank Mr. Pierre Morales, Dr. Cora Cravero and all medical secretaries who kindly helped to provide the necessary data for this analysis. 


\begin{abstract}
INTRODUCTION: Youths with severe and persistent irritability have a particularly high rate of school failures and learning difficulties. The aim of this study was to determine whether inpatient adolescents with Disruptive Mood Dysregulation Disorder (DMDD) have more motor and/or language impairments compared to patients with other psychiatric disorders.
\end{abstract}

METHODS: A retrospective chart review of all consecutive cases admitted in two adolescent inpatient units between January 2017 and December 2018 was conducted $(\mathrm{N}=191)$. All patients received multi-disciplinary clinical and developmental assessments. For a subtest of subjects, additional standardized tests were used to document motor and language impairments. In this clinical chart 53 adolescents with a DMDD (mean age $13.6 \pm 1.5$, min 12, max 16, 70\% males) were compared to patients with a major depressive disorder (MDD, $n=64$, mean age $15.3 \pm 1.6$, $52 \%$ males) and patients with a non-mood disorder (NMD, $n=61$, mean age $14.4 \pm 1.55,59 \%$ males).

RESULTS: Among inpatients with DMDD, $71 \%$ had an associated motor and/or language disorder, with combined forms in around two-thirds of cases. Compared to youths with MDD, participants with DMDD were more likely to have an associated developmental coordination disorder $(67 \%$ vs. $22 \%, O R=4.7)$ and a written language disorder $(35 \%$ vs. $10 \%, O R=4.6)$. While $31 \%$ of inpatients with DMDD had an associated communication/oral language disorder, this rate was not statistically different from those observed in the MDD group $(11 \%, O R=3.2)$. The frequencies of motor and language impairments were not statistically different between participants in the DMDD group and in the NMD group.

CONCLUSION: The high rate of motor and written language disorders found in DMDD patients may partly account for their academic difficulties. Such finding, if confirmed, supports 
systematic screening of motor and written language impairments in youths with chronic irritability and suggests remediation potential.

KEYWORDS: disruptive mood dysregulation disorder, chronic irritability, hospitalization, language disorder, communication disorder, learning disabilities, motor disorder, developmental coordination disorder, cognitive impairments, depressive disorder

\section{INTRODUCTION}

\subsection{General information about DMDD}

The Disruptive Mood Dysregulation Disorder (DMDD) is a childhood-onset psychiatric disorder newly included in the fifth edition of the Diagnostic and Statistical Manual of Mental Disorders (DSM-5) [1]. Youths with DMDD suffer from having a chronically irritable mood associated with repeated temper outbursts disproportionate for the developmental level. While the prevalence of DMDD is around $0.8-3.3 \%$ in the general population, it is overrepresented in mental health care services, with rates between $8 \%$ and $31 \%$ across sites [2]. Such a discrepancy is not very surprising as irritability, the core symptom of DMDD, is one of the most common reasons caregivers bring youths to outpatient treatment [3].

\subsection{School impairments in DMDD patients}

A high level of impairments in school functioning was constantly reported in youths with DMDD in community-based and clinical studies [4-8]. Margulies et al. [8] noted that children with DMDD are eight times more likely to report any problem with his/her teachers and nine 
times more likely to be suspended from school compared to healthy children. Other reports have shown that youths with DMDD have lower academic performance compared to youths with other psychiatric disorders [4-7]. The academic difficulties reported by children with DMDD sometimes persist into adulthood. Copeland et al. [9] showed that young adults who received a diagnosis of DMDD at age 10 were about twice as likely to fail to receive a high school diploma and to not go to college compared to those with another childhood-onset psychiatric disorder.

Several factors may affect the level of school functioning in youths with DMDD. School problems may be directly related to child's symptoms. For example, irritability and associated behaviors (e.g., reactive aggressive behavior) could affect the child's relationships with teachers and others schoolmates which could result in persisting conflicts within the classroom making it difficult to ensure a secure and supportive learning environment. Other co-occurring factors associated with DMDD could influence academic success in these patients, such as parental psychiatric problems [7], a high rate of psychosocial adversity and socio-economic difficulties [4], or comorbid psychiatric/developmental disorder [5,10]. Among these factors, the cooccurrence of developmental/learning disabilities are particularly worth identifying in these patients as they represent treatable conditions resulting in educational improvement when adequately addressed.

\subsection{Learning/developmental difficulties in youths with chronic irritability}

Surprisingly, few studies have examined the relationship between DMDD and developmental/learning disorders except for attention deficit disorder [11]. Preliminary evidence for a possible association between DMDD and learning disabilities was gained from case-series [12], chart-review studies [7,13] and epidemiological study [4]. In a large cross 
sectional community-based study conducted in 6,483 adolescents, Althoff, et al. (2016) found that parents of adolescents with DMDD symptoms were 1.7 times more likely to report a history of learning difficulties in their child compared to parents of children with an anxiety disorder, a bipolar disorder or an attention deficit disorder. Carlson et al. [12] reported that among inpatients those with any rages were 5.5 times more likely to present a learning/language disorder compared to those without ( $83 \%$ vs. $47 \%$ ). As noted by the authors, the lack of awareness of learning/developmental disabilities in patients with chronic emotional dysregulation may represent a missed opportunity to provide remediation interventions and ultimately to gain clinical improvement.

Previous studies have shown that youths with chronic irritability performed poorer in stop-signal task, a psychological task measuring motor inhibition, compared to children with other psychiatric disorders $[14,15]$. Whether difficulties in other components of motor skill (e.g., fine motor skill, imitation, visuo-spatial abilities) exist in youths with chronic irritability has never been investigated. Children with poor motor skills may be more likely to experience chronic negative mood, in particular in school, in response to repeated learning difficulties or peer rejection [16]. However, for children with poor motor skills and depressed mood the exclusion from certain activities involving motor cooperation could result in missed opportunities to refine their emotional regulation strategies in an extra-familial context [17]. Motor remediation or interventions enhancing participation with peers could be useful in this context to break the vicious circle of rejection, depressed mood and poor emotional regulation.

Several lines of research suggest that language difficulties are worth investigating in youths with chronic irritability. Child language delays and behavior problems, especially those involving poorly regulated anger, have been found to be associated both in clinical and nonclinical samples [18-20]. Longitudinal studies have shown direct evidence for relations among growth in language skills, decline in anger reactivity, and increase in self-regulatory strategy 
use $[21,22]$. In the same way, several interventions that teach children to use words to deal with frustration or to improve emotional categorization have shown a positive impact on socioemotional competence $[23,24]$.

As reading and writing are involved in almost all learning activities in schools, difficulties in these domains could contribute to the high rate of academic failure observed in youths with DMDD. The emergence of reading and writing skills involves the integrity of several acquired competences in language (e.g., phonological awareness) and motor domains (e.g., visuo-spatial, fine motor skill). It is therefore likely that difficulties in one of these domains could affect reading/writing performances.

\subsection{Aims of the study}

We used a retrospective chart review to determine the frequencies of motor and/or language developmental difficulties in inpatients with DMDD. Such developmental difficulties were measured in three ways: (i) the frequency of parent-reported delay and/or abnormal development in the domain considered, (ii) the frequency of associated diagnoses of developmental coordination disorder, communication/oral language disorder, and written language disorder and, (iii) the description of the detailed motor and/or language tests performed in a subset of patients prior or during the hospitalization. Inpatient adolescents with DMDD were compared to inpatients with Major Depressive Disorder without DMDD (MDD group) and to inpatients with non-mood disorder without DMDD (NMD, mainly psychotic and severe neurodevelopmental disorders). We hypothesized that the rate of developmental motor and language disorders would be higher in the DMDD group compared to the MDD group. No apriori-hypothesis was made for the difference between the DMDD and the NMD groups. We expected that DMDD youths would show impairments in multiple developmental domains, i.e., 
many of these patients having a combined form of developmental impairments in line with the observation provided by Carlson et al. [12]. Using an exploratory approach, the difficulties in several components of motor and language abilities were examined in the subsample of DMDD patients who had standardized tests:

- For motor development we paid particular attention to perceptive and motor abilities involved in the development of children's socio-emotional competence: motor imitation involved in contingent early-interaction with caregivers and later with peers [25,26]; fine motor ability [27], and visuo-spatial skill involved in cognitive perspective-taking [17].

- For oral language development, we examined specifically the semantic component of spoken language (vocabulary understanding), considering the relation between lexical enrichment and emotional regulation competencies reported [28,29]. While other aspects of language typically affected in communication/oral language disorder such as phonological awareness and syntax were also examined, the pragmatic component of language was not.

- For written language, we in particular examined the speed and the quality of the reading and the writing, regarded to be strong predictors for school performances [30,31].

\section{METHODS}

\subsection{Study design and setting}

Data from the medical records of all patients hospitalized between January 1, 2017 to December 31, 2018 in the two adolescent units of the child and adolescent psychiatric department of a tertiary university care center were extracted $(\mathrm{N}=191)$. Two researchers (a 
psychologist and a resident in psychiatry) used a 72-item computerized questionnaire to extract relevant information based on all clinical and paramedical charts available. All data was crosschecked by the senior psychiatrist who directly cared for each adolescent. The inter-rater reliability of the chart review instrument based on the analysis of ten randomly selected files was good $(\kappa=.80)$. The data collected encompassed (i) socio-demographic characteristics, (ii)

clinical features and symptom severity, (iii) developmental history and associated medical conditions, (iv) school functioning and psychosocial factors. The levels of functioning and symptom severity were assessed using questionnaires routinely used in the units: the ChildrenGlobal Assessment of Functioning scale (C-GAF) [32], the Clinical Global ImpressionsSeverity scale (CGI-S), and the CGI-Improvement Scale (CGI-I) [33]. The study followed general recommendations for retrospective chart review [34]. This project was designated as IRB exempt due to its retrospective design, patient de-identification, and the use of routine questionnaires.

\subsection{Participants}

We used a two-step procedure for the diagnostic of DMDD. Firstly, we carefully reviewed all charts searching for symptoms of chronic irritability (i.e., persistent irritable mood and/or anger feeling and/or impulsive/reactive/hostile aggressive behavior, and/or temper tantrums, for at least 12 months). We also examined the list of patients who required seclusion and/or intra-muscular treatment during the study period. Secondly, clinical data of inpatient adolescents positively screened were abstracted using a specific instrument based on the criteria for the temper dysregulation disorder with dysphoria, a research entity developed by the DSM5 Task Force prior to the publication of the final DMDD criteria [35]. Each item was endorsed as present or absent or unknown. The final diagnostic was endorsed only if participants matched all diagnostic criteria, including duration criteria, cross-domain impairment, and age of onset 
(Table S1). The psychometric properties of this ad-hoc diagnostic section for DMDD were explored in another sample of 12 to 15 year-old outpatients (internal validity Chronbach's $\alpha=0.90$, test-retest reliability $\kappa=.87$ ) [36]. All other diagnoses were based on discharge diagnoses and follow the DSM-5 formulation [1].

[Insert Figure 1 about here]

\subsection{Measurements}

All patients hospitalized in the adolescent units received a multidimensional psychiatric and developmental assessment based on repeated family interviews, clinical interviews and observations of participants in various contexts, including in the hospital school center. Standardized assessments performed prior to the hospitalization were systematically collected and reread.

In-depth motor assessment encompassed four standardized tests ascertaining different components of motor activity:

- The Movement Assessment Battery for Children 2nd edition (MABC-2) is a comprehensive measurement of motor skills used for the detection of movement difficulty in children [37] or as a diagnostic tool for developmental coordination disorder [38]. The test comprises 11 items grouped in 3 subtests: Manual Dexterity, Aiming and Catching, and Balance. The raw scores are converted to percentile rank: a score between the 6 th and 15 th percentile represents a risk of having a movement difficulty and a score at or below the 5th percentile represents significant movement difficulty. Psychometric properties are good and MABC-2 AB3 version was standardized for youths between 3-16 years.

- The Developmental Test of Visual Perception, 2nd edition (DTVP-2) is a 
comprehensive visual-perceptual evaluation [39] which encompasses eight subtests that measure different visual perceptual and visual-motor parameters. The raw scores are calculated as the sum of each subtest, which can be converted into percentiles. Sums of standard scores can be converted to two composite quotients: the motor-reduced visual perception quotient (visual-cognitive aspect) and the visual-motor integration quotient (visual-motor aspect). Psychometrics properties of the DTPV-2 are good [39,40], and the scores were standardized for youths between 4-10 years.

- The Manual and Digital Gnosopraxia Test (EMG) is a specific measure of manual praxis based on gesture imitation for hands and digits [41]. This is a modified version of Bergès, Lézine [42]. A total composite score is based on success rate for gesture imitation and motor planification.

- The Brief assessment of writing skill in adolescent (BHK-ado) [30] is a French adaptation for adolescents of the BHK test created by Hamstra-Bletz [43]. The test consists of a copy of a standardized test during five minutes on a blank paper. Analyses of writing ability is based on nine items measuring the quality of the writing and speed. Psychometric properties were assessed in a French sample of adolescents [44].

In-depth language assessment encompassed several tests ascertaining different components of language activity. For oral language, phonological skill was measured based on the performances at two items (repetition of the logatom, suppression of the last phonem) of the Evaluation des Fonctions cognitives et des Apprentissages (EDA) [45]. Syntax and morphology skills were ascertained based on two items of the EDA (syntax understanding, sentence completion). The semantics component of oral language was assessed in two ways: with two items of the EDA for the receptive domain (lexical understanding, picture designation) and with the Peabody Picture Vocabulary Test (PPVT) [46] for the expressive domain. Different tests were used for the assessment of written language. Reading skills were ascertained with the 
$L M C$-R test [47], the L2MA-2 test [48], Odédys 2 [49] or Evaléo 6-15 [31]. Writing skills were based on two items of the EDA (dictation and text transcription), Alouette- $R$ test [50] or the Batterie d'Evaluation de la Lecture et de l'Orthographe (BELO) test [51]. The choice of the appropriate test was left to the speech therapist.

The indication for performing additional tests (e.g., sensory-processing, attentional, logicomathematic) was discussed case-by-case during weekly multidisciplinary meetings (including two child psychiatrists, a psychologist, a motor therapist, a speech therapist and two schoolteachers). The scores at the different tests were standardized based on the scores of typically developing same-age adolescents' performances such as provided by manuals. Results were reported as Standard Deviation (SD) or percentile. Standard errors have been transformed in confidence intervals to facilitate the interpretation of the results. When several standardized assessments were available, only the last one was reported.

\subsection{Statistical analyses}

For the description of the sample, ANOVA or Kruskall-Wallis tests were used to compare quantitative variables and Chi-squared or Fisher's exact tests for qualitative variables, depending on assumptions validity. Quantitative variables were described using mean and standard deviation and qualitative variables using number and percentage of occurrences. OddRatios $(O R)$ were presented with their confidence intervals and Cramer's $\phi$ (Phi) correlation coefficients for effect sizes.

To document the association between motor impairments and DMDD, a Fisher's exact test was used to compare the proportions of inpatient adolescents with developmental coordination disorder between the DMDD group, the MDD group, and the NMD group. A similar analysis was performed to compare the proportions of parent-reported delays in motor development 
between the DMDD, MDD, and NMD groups. Univariate analyses were used to describe the results of the battery of motor tests conducted in the subset of inpatients with DMDD who had in-depth motor assessment $(\mathrm{n}=24)$.

To document the association between language impairments and DMDD, a Fisher's exact test was used to compare the proportions of inpatient adolescents with communication/oral language disorder and written language disorder between the DMDD group, the MDD group, and the NMD group. A similar analysis was performed to compare the proportions of parentreported delays in language development between the DMDD, MDD, and NMD groups. Univariate analyses were used to detail the results of the battery of language tests conducted in the subset of inpatients with DMDD who had in-depth language assessment ( $\mathrm{n}=29)$.

Analyses were run on R 3.4.0 and a p-value less than 0.05 was considered significant. Applying the Bonferroni correction for planned comparisons for the first two aims of the study this p-value was divided by 15 . The corrected threshold for statistical significance was therefore 0.0038. We proceeded to subgroups analyses to determine whether the rates of developmental motor and language disorders differed in DMDD patients with regards to the ADHD status (Table S2).

\section{RESULTS}

\subsection{Description of the sample}

Among the 191 inpatient adolescents consecutively admitted during the study period, 67 were positively screened for chronic irritability and 53 matched all criteria for DMDD. All inpatients with chronic irritability without DMDD ( $\mathrm{n}=14$, Mean age $14.4 \pm 1.9,64 \%$ males) had severe neurodevelopmental conditions and/or chronic psychiatric disorders (intellectual 
disability $\mathrm{n}=11$, autistic spectrum disorder $\mathrm{n}=4$, organic neurological disorder $\mathrm{n}=7$, schizophrenia disorder $n=2$, bipolar disorder $n=3$, chronic tic disorder $n=1$ ).

As presented in Table 1, inpatients with DMDD were mostly boys and were younger than inpatients in the MDD and NMD groups. The most frequent psychiatric disorders associated with DMDD were disruptive behavioral disorder, anxiety disorder and attention deficit disorder. The C-GAF score at admission, the CGI-S score, and the CGI-I score were not statistically different among the three groups.

[Insert Table 1, about here]

\subsection{Motor developmental difficulties}

In our clinical chart, $67 \%$ of the DMDD inpatients had an associated developmental coordination disorder which represents $80 \%$ of those who had in-depth motor assessment $(23 / 29)$ and $20 \%$ of those who did not (5/24). The rate of developmental coordination disorder was higher in the DMDD group than in the MDD group $(O R=4.6695 \% \mathrm{CI}: 2.09,10.41, \phi=$ $.32, p<.001)$ but was not statistically different from the NMD group $(O R=1.7695 \%$ CI: 0.84 , $3.70, \phi=.29, p=.559)$ (Table 2). The frequency of parent-reported delay and/or abnormal motor development was higher in the DMDD group compared to the two other groups.

Inpatient adolescents with DMDD who had in-depth motor assessment had problematic scores in tests measuring fine motor skills such as the EMG manual imitation score and the subscore of the MABC-2 for manual dexterity. They had scores in the normal range for the tests ascertaining gross motor skills (i.e., the MABC-2 total score) and visuo-spatial skills (i.e., the DTVP-2) and scored low in the BHK-ado, a test of graphism and writing ability.

[Insert Table 2, about here] 
[Insert Table 3, about here]

\subsection{Language developmental difficulties}

In our clinical chart, $31 \%$ of the DMDD inpatients had an associated communication/oral language disorder; this represent $47 \%$ of those who had in-depth language assessment $(11 / 24)$ and $0 \%$ of those who did not $(0 / 29)$. Considering corrected p-value, the rate of communication/oral language disorder was not statistically different between the DMDD and the MDD groups $(O R=3.2195 \% \mathrm{CI}: 1.20,8.61, \phi=.22, p=.019)$ or between the DMDD and the NMD group $(O R=1.6195 \%$ CI: $0.67,3.84, \phi=.15, p=.367)$ (Table 2). Parent-reported delay and/or abnormal language development were not statistically different among the three groups.

As presented in Table 4, inpatients with DMDD who had in-depth language assessment had low scores in tests measuring phonological awareness (repetition of logatom, suppression of the last phonem), syntax and sematic expression (sentence completion, picture denomination). However, tests measuring the receptive component of spoken language (lexical understanding, picture designation, syntax understanding) were in the normal range.

[Insert Table 4, about here]

In our clinical chart, 35\% of DMDD inpatients had a written language disorder; this represents $50 \%$ of those who had in-depth language assessment (12/24) and $11 \%$ of those who did not (3/29). The rate of written language disorder was higher in the DMDD group than in the MDD group $(O R=4.5695 \% \mathrm{CI}: 1.65,12.64, \phi=.59, p=.002)$ but not statistically different compared to inpatients in the NMD group $(O R=4.3395 \% \mathrm{CI}: 1.56,12.02, \phi=.58, p=.005)$ (Table 2). 
Inpatients with DMDD who had in-depth language assessment had scores in tests measuring reading ability and writing skill between -1 and -2 SD (Table 4).

\subsection{Combined developmental difficulties}

Around $71 \%$ of inpatients with DMDD had an associated motor and/or language developmental disorder. A combined form of motor and/or language disorders concerns almost $46 \%$ inpatients with DMDD which is higher than in the MDD and NMD groups (Table 2). Only two subjects with DMDD had a written language disorder without also having a communication/oral language disorder.

\section{DISCUSSION}

\subsection{Interpretation of the main finding}

We found a very high rate of developmental motor and language disorders in inpatients with DMDD (71\%) compared to inpatients with MDD or NMD (respectively, $28 \%$ and $36 \%$ ). As a comparison, a 7\% rate of learning disabilities was reported among the DMDD youths in the chart-review of 6-17-year-old inpatients conducted by Tufan et al. [13]. A 19\% rate of learning disabilities was reported in DMDD patients in a Canadian 7 to17-year-old outpatient sample particularly enriched in mood disorders, although this rate was not statistically different from subjects with major depressive disorder (11\%) [7].

This finding should be interpreted in the light of the risk of sampling bias. Most of the participants' hospitalizations were planned to provide a second opinion and adequate treatments for severe forms of psychiatric disorders. This may explain why this sample is particularly enriched in complex forms of psychiatric and developmental disorders. In addition, our 
department includes an expert center for learning disabilities which had referred some patients. Furthermore, only adolescents were included in this research, unlike previous studies reporting the rate of learning disabilities in all DMDD patients $[13,12,7]$. By doing that, we may have selected a sample of particular severity as many prepubertal children with DMDD have only a transitory course of symptoms [6]

Several competing hypotheses could explain the high rate of co-occurrence between motor and/or language disorders and DMDD. Aberrancies in the motor and language domains could co-occur with irritability i) because they increase the frequency of frustrating events, in particular academic failure and difficult peer-relations $[16,22]$, ii) because they are associated with delay in emotion-regulation skills $[27,21]$, or iii) due to shared risk factors [7,52]. The results presented here do not allow us to distinguish between these three possibilities.

In our research we found that youths with DMDD had low scores in motor tasks testing motor imitation and fine motor skills. In contrast, balance and visuo-spatial skills were in the normal range. Such findings, while preliminary, are interesting considering the role of imitation in the emergence of young children's socio-emotional competence [26]. Difficulties in imitating facial emotion has been also associated with impairments in emotional recognition [53] and poor emotional awareness [54], two difficulties reported in DMDD patients [2]. The relatively good performance of DMDD in visuo-spatial tasks should be interpreted with caution, considering a possible ceiling effect for the DTVP-2 test, as the normative scores were extracted from a children sample.

We found that almost a third of DMDD patients had an associated communication/oral language disorder. However, using a more stringent criteria for statistical significance the difference between the patients with DMDD and the two other clinical control groups were no longer significant. In-depth language assessment tests showed that the subsample with DMDD 
and oral language impairments were particularly affected in the expressive domain of language (e.g., ascertained with the PPVT test) while they had scores in the normal range for the receptive domain (lexical understanding, picture denomination of the EDA test). This reflects the importance of considering not only the theoretical knowledge of youths' vocabulary but also how the lexical terms are actually used in everyday situations in youth with emotional problems and oral language impairments [55]. Suboptimal scores in other components of spoken language skills (i.e., phonology, syntax) were consistent with the relations reported between these components and early behavioral problems [56].

As the content of many therapeutic interventions for emotional disorders in adolescents are delivered orally (e.g., structured psychotherapies, group interventions, psychoeducation, family-focused interventions), a low level of oral language competence may also be worth identifying in youths with DMDD as it could moderate the response to therapeutic interventions. It remains to be seen whether interventions focusing on enhancing verbal emotional expression that proved effective in improving socio-emotional competence in children [23] could be successfully applied to DMDD patients with difficulties in oral language skills.

Youths with DMDD were particularly impaired in reading and writing competency (i.e., BHK-ado, dictation, text transcriptions) in line with our initial hypothesis. Nearly one third of DMDD patients had a written language disorder, and the lowest scores in standardized language tests were observed for tasks ascertaining reading and writing skills. In addition to the difficulties in phonology reported in DMDD subjects here, DMDD patients may be affected in several cognitives domains involved in the reading process such as attention [2] and inhibition $[14,15]$. Logically, the combination of reading/spelling difficulties and fine motor/graphism problems (i.e., as ascertained by the item Manual Dexterity of the MABC-2) in DMDD subjects results in poor writing performance This is particularly true for DMDD patients, as many of 
them have combined forms of learning/developmental disorders. The difficulties in text transcription based on visual or auditory informations could affect all learning activities, accounting for the low level of academic achievement observed in DMDD patients [4-8] .

\subsection{Limitations}

First, and as previously mentioned, this sample reflects adolescents referred in a tertiary university care referral center. How these findings apply to adolescents with less severe symptoms remains to be studied. A non-irritable ADHD sample might have been also worth including as a comparison group to account for the confounding effect of ADHD. Second, this chart-review study may be prone to a measuring bias, due to missing or incomplete charts. Standardized assessments were only performed in a subgroup of non-randomly selected patients resulting in a possible sampling bias and an overestimation the rates of motor and language impairments. To limit this risk, the link between DMDD and developmental motor and language disorders was estimated by combining different measures: rates of DSM-5 psychiatric disorders, parent-reported information, and profile of impairments based on standardized tests in subsets of patients. Third, the diagnostic of DMDD was set up retrospectively on the basis of the temper dysregulation with dysphoria disorder whose diagnostic criteria differ slightly from DMDD. The use of this proxy diagnostic procedure was regarded as acceptable as all patients with temper dysregulation with dysphoria would match the less stringent DMDD criteria.

\subsection{Clinical and research implications}

If confirmed, this work will support the use of standardized screening assessment for developmental difficulties in help-seeking populations of adolescents with DMDD. Further 
studies would help to elucidate how difficulties in motor and language domains play a role in the propensity to anger reaction and temper outbursts observed in DMDD youths. For example, longitudinal studies of preschool children with repeated assessment of developmental steps, anger reactivity and behavioral measures could provide opportunities to understand the temporal interplay between these dimensions. Such studies may contribute to the development of promising therapeutic opportunities to reduce the academic difficulties of youths with DMDD.

\subsection{Conclusion}

In the current study, we found that a vast majority of inpatient youths with DMDD presented an associated diagnosis of developmental motor and written language disorders. Most of these adolescents with DMDD had combined forms of developmental impairments. Considering the current lack of therapeutic opportunity for DMDD youths, awareness of these associated conditions could be beneficial. Clinicians and researchers should remain careful that behavioral expressions of anger do not distract them from the bigger picture of developmental impairments in DMDD patients.

LIST OF ABBREVIATIONS USED: Disruptive Mood Dysregulation Disorder (DMDD); Bipolar Disorder (BD); Adjustment Disorder (AD); Post-Traumatic Stress Disorder (PTSD); Attention Deficit Hyperactivity Disorder (ADHD); Disruptive Behavioral Disorder (DBD); Tourette Syndrome (TS); Brief Psychotic Disorder (BPD); Intellectual Disability (ID); Autistic Spectrum Disorder (ASD); Children-Global Assessment Scale (CGAS); Clinical Global Impressions-Severity (CGI-S); Clinical Global Impressions-Improvement (CGI-I); Wechsler Intelligence Scale for Children - Fourth Edition (WISC-IV); Wechsler Intelligence 
Scale for Children - Fifth Edition (WISC-V); Movement Assessment Battery for Children 2nd edition (MABC-2); Manual and Digital Gnosopraxia Test (EMG); Developmental Test of

Visual Perception 2nd edition (DTVP-2); Brief assessment of writing skill in adolescent (BHK-ado); Evaluation des Fonctions cognitives et des Apprentissages (EMA); Peabody Picture Vocabulary Test (PPVT).

\section{REFERENCES}

1. American Psychiatric Association (2013) Diagnostic and Statistical Manual of Mental Disorders, 5th Edition. American Psychiatric Association, Arlington, VA

2. Vidal-Ribas P, Brotman MA, Valdivieso I, Leibenluft E, Stringaris A (2016) The Status of Irritability in Psychiatry: A Conceptual and Quantitative Review. J Am Acad Child Adolesc Psychiatry 55 (7):556570. doi:10.1016/j.jaac.2016.04.014

3. Yeh M, Weisz JR (2001) Why are we here at the clinic? Parent-child (dis)agreement on referral problems at outpatient treatment entry. J Consult Clin Psychol 69 (6):1018-1025

4. Althoff RR, Crehan ET, He JP, Burstein M, Hudziak JJ, Merikangas KR (2016) Disruptive Mood Dysregulation Disorder at Ages 13-18: Results from the National Comorbidity Survey-Adolescent Supplement. J Child Adolesc Psychopharmacol 26 (2):107-113. doi:10.1089/cap.2015.0038 5. Copeland WE, Angold A, Costello EJ, Egger H (2013) Prevalence, comorbidity, and correlates of DSM-5 proposed disruptive mood dysregulation disorder. Am J Psychiatry 170 (2):173-179. doi:10.1176/appi.ajp.2012.12010132

6. Axelson D, Findling RL, Fristad MA, Kowatch RA, Youngstrom EA, Horwitz SM, Arnold LE, Frazier TW, Ryan N, Demeter C, Gill MK, Hauser-Harrington JC, Depew J, Kennedy SM, Gron BA, Rowles BM, Birmaher B (2012) Examining the proposed disruptive mood dysregulation disorder diagnosis in children in the Longitudinal Assessment of Manic Symptoms study. J Clin Psychiatry 73 (10):13421350. doi:10.4088/JCP.12m07674

7. Benarous X, Renaud J, Breton JJ, Cohen D, Labelle R, Guilé J-M (2020) Are youths with disruptive mood dysregulation disorder different from youths with major depressive disorder or persistent depressive disorder? Journal of Affective Disorders. doi:https://doi.org/10.1016/j.jad.2020.01.020 8. Margulies DM, Weintraub S, Basile J, Grover PJ, Carlson GA (2012) Will disruptive mood dysregulation disorder reduce false diagnosis of bipolar disorder in children? Bipolar Disord 14 (5):488-496. doi:10.1111/j.1399-5618.2012.01029.x

9. Copeland WE, Shanahan L, Egger H, Angold A, Costello EJ (2014) Adult diagnostic and functional outcomes of DSM-5 disruptive mood dysregulation disorder. Am J Psychiatry 171 (6):668-674. doi:10.1176/appi.ajp.2014.13091213

10. Benarous X, Consoli A, Cohen D (2020) Definition and features of depressive disorder in children and adolescents. In: Xie P (ed) Overview and advance in clinical studies of depressive disorder. Springer,

11. Shaw P, Stringaris A, Nigg J, Leibenluft E (2014) Emotion Dysregulation in Attention Deficit Hyperactivity Disorder. American Journal of Psychiatry 171:276-293

12. Carlson GA, Potegal M, Margulies D, Gutkovich Z, Basile J (2009) Rages--what are they and who has them? J Child Adolesc Psychopharmacol 19 (3):281-288. doi:10.1089/cap.2008.0108 
13. Tufan E, Topal Z, Demir N, Taskiran S, Savci U, Cansiz MA, Semerci B (2016) Sociodemographic and Clinical Features of Disruptive Mood Dysregulation Disorder: A Chart Review. J Child Adolesc Psychopharmacol 26 (2):94-100. doi:10.1089/cap.2015.0004

14. Hoeksma JB, Oosterlaan J, Schipper EM (2004) Emotion regulation and the dynamics of feelings: a conceptual and methodological framework. Child Dev 75 (2):354-360. doi:10.1111/j.1467-

8624.2004.00677.x

15. Deveney CM, Connolly ME, Jenkins SE, Kim P, Fromm SJ, Pine DS, Leibenluft E (2012) Neural recruitment during failed motor inhibition differentiates youths with bipolar disorder and severe mood dysregulation. Biol Psychol 89 (1):148-155. doi:10.1016/j.biopsycho.2011.10.003

16. Mammarella I, Ghisi M, Bomba M, Bottesi G, Caviola S, Broggi F, Nacinovich R (2016) Anxiety and Depression in Children With Nonverbal Learning Disabilities, Reading Disabilities, or Typical Development. Journal of learning disabilities 49:130-139. doi:10.1177/0022219414529336 17. Xavier J, Tilmont E, Bonnot O (2013) Children's synchrony and rhythmicity in imitation of peers: toward a developmental model of empathy. Journal of physiology, Paris 107 (4):291-297. doi:10.1016/j.jphysparis.2013.03.012

18. Baker L, Cantwell DP (1992) Attention deficit disorder and speech/language disorders. Comprehensive Mental Health Care 2 (1):3-16

19. Cohen JS, Mendez JL (2006) Emotion regulation, language ability, and the stability of preschool children's peer play behavior. Early Education and Development 20:1016-1037.

doi:https://doi.org/10.1080/10409280903305716

20. Irwin JR, Carter AS, Briggs-Gowan MJ (2002) The social-emotional development of "late-talking" toddlers. J Am Acad Child Adolesc Psychiatry 41 (11):1324-1332. doi:10.1097/00004583-20021100000014

21. Chow JC, Ekholm E, Coleman H (2018) Does oral language underpin the development of later behavior problems? A longitudinal meta-analysis. School Psychology Quarterly 33 (3):337-349. doi:10.1037/spq0000255

22. Roben CK, Cole PM, Armstrong LM (2013) Longitudinal relations among language skills, anger expression, and regulatory strategies in early childhood. Child Dev 84 (3):891-905.

doi:10.1111/cdev.12027

23. Izard CE, King KA, Trentacosta CJ, Morgan JK, Laurenceau JP, Krauthamer-Ewing ES, Finlon KJ (2008) Accelerating the development of emotion competence in Head Start children: effects on adaptive and maladaptive behavior. Dev Psychopathol 20 (1):369-397.

doi:10.1017/S0954579408000175

24. Ornaghi V, Brockmeier J, Grazzani I (2014) Enhancing social cognition by training children in emotion understanding: a primary school study. Journal of experimental child psychology 119:26-39. doi:10.1016/j.jecp.2013.10.005

25. Decety J, Smith KE, Norman GJ, Halpern J (2014) A social neuroscience perspective on clinical empathy. World Psychiatry 13 (3):233-237. doi:10.1002/wps.20146

26. Nadel-Brulfert J, Baudonniere PM (1982) The Social Function of Reciprocal Imitation in 2-Year-Old Peers. International Journal of Behavioral Development 5 (1):95-109.

doi:10.1177/016502548200500105

27. Mendes LST, Manfro GG, Gadelha A, Pan PM, Bressan RA, Rohde LA, Salum GA (2018) Fine motor ability and psychiatric disorders in youth. European Child \& Adolescent Psychiatry 27 (5):605-613. doi:10.1007/s00787-017-1091-y

28. Vallotton C, Ayoub C (2011) Use Your Words: The Role of Language in the Development of Toddlers' Self-Regulation. Early Child Res Q 26 (2):169-181. doi:10.1016/j.ecresq.2010.09.002 29. Cole P, Armstrong L, Pemberton C (2010) The role of language in the development of emotion regulation. In: Calkins S, Bell M (eds) Development at the intersection of cognition and emotion. APA, Washington, D.C.,

30. Charles M, Soppelsa R, Albaret J-M (2003) BHK - Echelle d'évaluation rapide de l'écriture chez I'enfant. Editions et Applications Psychologiques, Paris 
31. Launay L, Maeder C, Touzin M, Roustit J (2018) Evaléo 6-15: batterie d'évaluation du langag écrit et oral. Ortho Edition, Isbergues

32. Jones SH, Thornicroft G, Coffey M, Dunn G (1995) A brief mental health outcome scale-reliability and validity of the Global Assessment of Functioning (GAF). Br J Psychiatry 166 (5):654-659

33. Busner J, Targum SD (2007) The clinical global impressions scale: applying a research tool in clinical practice. Psychiatry (Edgmont (Pa : Township)) 4 (7):28-37

34. Gearing RE, Mian IA, Barber J, Ickowicz A (2006) A Methodology for Conducting Retrospective Chart Review Research in Child and Adolescent Psychiatry. Journal of the Canadian Academy of Child and Adolescent Psychiatry 15 (3):126-134

35. APA Taskforce DSM-5 (2010) Justification for temper dysregulation disorder with dysphoria. In: Association AP (ed). Washington, DC,

36. Boudjerida A, Labelle R, Bergeron L, Berthiaume C, Breton JJ (2018) Disruptive Mood

Dysregulation Disorder Scale in Adolescence. Paper presented at the International Association for

Child \& Adolescent Psychiatry and Allied Professions, Prague, 2018

37. Henderson SE, Sugden DA, Barnett AL (2007) MovementAssessment BatteryforChildren, 2ndEdn. Pearson, London

38. Wagner M, Jascenoka J, Petermann F, Bös K (2010) Factorial validity of the Movement

Assessment Battery for Children-2 (age band 2). Research in developmental disabilities 32:674-680. doi:10.1016/j.ridd.2010.11.016

39. Hammill DD, Voress JK, Pearson NA (1993) Developmental Test of Visual Perception, Second Edition (DTVP-2). In. Pro-Ed, Austin, Texas,

40. Brown T, Hockey SC (2013) The Validity and Reliability of Developmental Test of Visual Perception-2nd Edition (DTVP-2). Physical \& Occupational Therapy In Pediatrics 33 (4):426-439. doi:10.3109/01942638.2012.757573

41. Vaivre-Douret L, Lalanne C, Ingster-Moati I, Boddaert N, Cabrol D, Dufier J (2011) Subtypes of developmental coordination disorder : research on their nature and etiology. Dev Neuropsychol 36:614-643. doi:10.1080/87565641.2011.560696

42. Bergès J, Lézine I (1963) Test d'imitation de gestes. Masson, Paris

43. Hamstra-Bletz L (1994) Dysgraphic handwriting compared with normal handwriting. Handwriting Review:121-127

44. Soppelsa R, Albaret J-M (2013) BHK Ado.

45. Billard C, Touzin M (2012) L’EDA : Évaluation Des fonctions cognitives et Apprentissages. Ortho Éditions.

46. Dunn LD, Dunn DM (2007) Peabody Picture Vocabulary Test, Fourth Edition. Pearson Education, 47. Khomsi A, Khomsi J (2003) BLI : Batterie de lecture informatisée. In. ECPA, Paris,

48. Chevrie-Muller C, Maillart C, Simon AM, Fournier S (2010) L2MA-2 Batterie langage oral, langage écrit, mémoire et attention. Pearson,

49. Jacquier-Roux M, Valdois S, Zorman M, Lequette C, Pouget $G$ (2005) Odédys, outil de dépistage des dyslexies. version 2. In: IUFM Académie de Grenoble C-SeLdpedn (ed). Université Pierre-Mendés France. doi:http://www.grenoble.iufm.fr/recherch/cognisciences

50. Lefavrais P (2005) L' Alouette-R. . Les Editions du Centre de Psychologie Appliquée, Paris

51. Pech-Georgel C, George F (2006) Batterie d'Evaluation de la Lecture et de l'Orthographe. In: Solal. Pech-Georgel C, George, F., Nazarian, B. (ed). AXU, Marseilles,

52. Munhoz TN, Santos IS, Barros AJD, Anselmi L, Barros FC, Matijasevich A (2017) Perinatal and postnatal risk factors for disruptive mood dysregulation disorder at age 11: 2004 Pelotas Birth Cohort Study. J Affect Disord 215:263-268. doi:10.1016/j.jad.2017.03.040

53. Wood A, Rychlowska M, Korb S, Niedenthal P (2016) Fashioning the Face: Sensorimotor Simulation Contributes to Facial Expression Recognition. Trends Cogn Sci 20 (3):227-240.

doi:10.1016/j.tics.2015.12.010

54. Trevisan DA, Bowering M, Birmingham E (2016) Alexithymia, but not autism spectrum disorder, may be related to the production of emotional facial expressions. Mol Autism 7:46.

doi:10.1186/s13229-016-0108-6 
55. Ridgeway D, Waters E, Kuczaj SA Acquisition of Emotion-Descriptive Language: Receptive and Productive Vocabulary Norms for Ages 18 Months to 6 Years. In, 1985.

56. Gremillion ML, Martel MM (2014) Merely misunderstood? Receptive, expressive, and pragmatic language in young children with disruptive behavior disorders. Journal of clinical child and adolescent psychology : the official journal for the Society of Clinical Child and Adolescent Psychology, American

Psychological Association, Division 5343 (5):765-776. doi:10.1080/15374416.2013.822306

\section{FIGURES CAPTIONS}

Figure 1. Flow-chart of the sample 

Table 1. Description of the subjects with DMDD, MDD and non-mood disorder

\begin{tabular}{|c|c|c|c|c|}
\hline & $\begin{array}{r}\text { DMDD } \\
(\mathrm{n}=53)\end{array}$ & $\begin{array}{l}\text { MDD } \\
(n=64)\end{array}$ & $\begin{array}{l}\text { NMD } \\
(\mathrm{n}=61)\end{array}$ & p-value \\
\hline \multicolumn{5}{|c|}{ Socio-demographic characteristics } \\
\hline Gender, female, $\mathrm{n}(\%)$ & $16(30 \%)$ & $31(48 \%)$ & $25(41 \%)$ & $.134+$ \\
\hline Age (y) $($ mean \pm SD) & $13.58 \pm 1.49^{\mathrm{a}}$ & $15.33 \pm 1.65^{b}$ & $14.42 \pm 1.55^{\mathrm{b}}$ & $<.001+t t^{* *}$ \\
\hline $\begin{array}{l}\text { Socio-economic status, high } \\
\text { and middle, } \mathrm{n}(\%)\end{array}$ & $31(59 \%)$ & $51(80 \%)$ & $48(79 \%)$ & $.017 \dagger$ \\
\hline \multicolumn{5}{|c|}{ School functioning and psychosocial factors } \\
\hline Prior grade repetition, $\mathrm{n}(\%)$ & $15(28 \%)$ & $13(20 \%)$ & $9(15 \%)$ & $.204 .201+\dagger$ \\
\hline $\begin{array}{l}\text { School non-attendance above } \\
3 \text { months, } \mathrm{n}(\%)\end{array}$ & $24(45 \%)$ & $32(51 \%)$ & $20(33 \%)$ & $.118 .139+\dagger$ \\
\hline School adaptations, $\mathrm{n}(\%)$ & $36(68 \%)$ & $29(46 \%)$ & $31(51 \%)$ & $.050 \dagger$ \\
\hline $\begin{array}{l}\text { Special educational facilities, } \\
\mathrm{n}(\%)\end{array}$ & $14(26 \%)^{a}$ & $6(10 \%)^{b}$ & $7(12 \%)^{b}$ & $.025 .030 t^{*}$ \\
\hline Foster care placement, $\mathrm{n}(\%)$ & $17(32 \%)^{\mathrm{a}}$ & $7(11 \%)^{b}$ & $4(7 \%)^{b}$ & $<.001+\dagger^{* *}$ \\
\hline $\begin{array}{l}\text { Home educative } \\
\text { assistance/report to child- } \\
\text { protection agencies, } \mathrm{n}(\%)\end{array}$ & $32(60 \%)^{a}$ & $19(30 \%)^{b}$ & $27(44 \%)^{a b}$ & $.004 \dagger^{* *}$ \\
\hline \multicolumn{5}{|c|}{ Developmental history and medical conditions associated } \\
\hline $\begin{array}{l}\text { Complicated pregnancy, } \mathrm{n} \\
(\%)\end{array}$ & $13(32 \%)^{a}$ & $16(25 \%)^{a}$ & $5(9 \%)^{b}$ & $.022 .020 t^{*}$ \\
\hline Acute fetal distress, $\mathrm{n}(\%)$ & $11(26 \%)$ & $12(19 \%)$ & $7(13 \%)$ & $.226 .349+\dagger$ \\
\hline Neurological disorder, $\mathrm{n}(\%)$ & $9(17 \%)^{a b}$ & $4(6 \%)^{b}$ & $13(22 \%)^{a}$ & $.045 .035 t^{*}$ \\
\hline $\begin{array}{l}\text { Chronic somatic condition } \\
\text { (non-neurological), } \mathrm{n}(\%)\end{array}$ & $29(55 \%)$ & $21(33 \%)$ & $24(40 \%)$ & $.054 \dagger$ \\
\hline \multicolumn{5}{|c|}{ Comorbid psychiatric disorders, $\%$} \\
\hline ADHD & $23(43 \%)^{a}$ & $4(6 \%)^{b}$ & $5(8 \%)^{b}$ & $<.001+\dagger^{* *}$ \\
\hline ASD & $3(6 \%)$ & $3(5 \%)$ & $14(23 \%)$ & .001 \\
\hline ANX & $29(55 \%)$ & $37(58 \%)$ & $23(38 \%)$ & $.057 .061+\dagger$ \\
\hline $\mathrm{ASD}$ & $3(6 \%)^{b}$ & $3(5 \%)^{b}$ & $14(23 \%)^{a}$ & $.003+\dagger^{* *}$ \\
\hline DBD & $36(68 \%)^{a}$ & $6(9 \%)^{b}$ & $11(18 \%)^{b}$ & $<.001+\dagger^{* *}$ \\
\hline ED & $1(2 \%)$ & $5(8 \%)$ & $1(2 \%)$ & $.226+t$ \\
\hline ID & $0^{\mathrm{b}}$ & $9(14 \%)^{a}$ & $13(22 \%)^{a}$ & $<.002001$ t十 $^{* *}$ \\
\hline SPD & $0^{b}$ & $3(5 \%)^{b}$ & $22(36 \%)^{a}$ & $<.001 .004 \dagger^{* *}$ \\
\hline STRDTSD & $16(30 \%)$ & $13(20 \%)$ & $23(38 \%)$ & $.100+\dagger$ \\
\hline TTS & $5(9 \%)$ & $1(2 \%)$ & $6(10 \%)$ & .084 t† \\
\hline $\begin{array}{l}\text { Number of psychiatric } \\
\text { diagnoses at discharge (mean } \\
\pm \text { SD) }\end{array}$ & $2.7 \pm 0.99^{\text {a }}$ & $2.09 \pm 0.94^{b}$ & $1.52 \pm 0.65^{\mathrm{c}}$ & $<.001+\dagger \dagger^{* *}$ \\
\hline \multicolumn{5}{|l|}{$\begin{array}{l}\text { Severity and treatment } \\
\text { response }\end{array}$} \\
\hline $\begin{array}{l}\text { History of admission in } \\
\text { inpatient structure, } \mathrm{n}(\%)\end{array}$ & $33(62 \%)^{a}$ & $29(45 \%)^{a b}$ & $18(30 \%)^{b}$ & $.002 t^{* *}$ \\
\hline $\begin{array}{l}\text { C-GAF at admission (mean } \\
\pm \mathrm{SD})\end{array}$ & $38.17 \pm 10.69$ & $38.44 \pm 11.68$ & $36.44 \pm 14.41$ & .422 t十† \\
\hline $\begin{array}{l}\text { C-GAF at discharge (mean } \\
\pm \mathrm{SD} \text { ) }\end{array}$ & $58.30 \pm 10.59$ & $62.52 \pm 13.15$ & $60.23 \pm 13.33$ & $.091+\dagger+$ \\
\hline
\end{tabular}




\begin{tabular}{|l|c|c|c|c|}
\hline $\begin{array}{l}\text { CGI-S at admission (mean } \\
\pm \text { SD) }\end{array}$ & $4.96 \pm 0.90$ & $4.83 \pm 1.00$ & $5.02 \pm 1.27$ & $.313++\dagger$ \\
\hline $\begin{array}{l}\text { CGI-I at discharge (mean } \\
\pm \text { SD) }\end{array}$ & $2.64 \pm 0.68$ & $2.44 \pm 0.90$ & $2.56 \pm 1.01$ & $.067++\dagger$ \\
\hline
\end{tabular}

\section{Note:}

† Chi-2 test; †† Fisher exact test; $\uparrow+\dagger$ Kruskal-Wallis test; * indicates $p<.05$. ** indicates $p<$ $.01{ }^{\mathrm{a}-\mathrm{bc}}$ Means in a row without a common superscript letter differ $(p<.05)$.

Disruptive Mood Dysregulation Disorder (DMDD); Anxiety Disorder (ANX); Adjustment Disorder (AD); Attention Deficit Hyperactivity Disorder (ADHD); Anxiety Disorder (ANX); Autistic Spectrum Disorder (ASD); Disruptive Behavioral Disorder (DBD); Eating Disorder (ED); Intellectual Disability (ID); Schizophrenia and other psychotic disorder (SPD); Trauma and Stress-Related and Trauma Related Disorder (STSRD); Attention Deficit Hyperactivity Disorder (ADHD); Disruptive Behavioral Disorder (DBD); Tics and Tourette Syndrome (TTS); Schizophrenia and other psychotic disorder (SPD); Intellectual Disability (ID); Autistic Spectrum Disorder (ASD); Children-Global Assessment Scale (CGAS); Clinical Global Impressions-Severity (CGI-S); Clinical Global Impressions-Improvement (CGI-I). 
Table 2. Prevalence of motor and language impairments in the DMDD, MDD and NDM groups

\begin{tabular}{|c|c|c|c|c|}
\hline & $\begin{array}{l}\text { DMDD } \\
(\mathrm{n}=53)\end{array}$ & $\begin{array}{l}\text { MDD } \\
(n=64)\end{array}$ & $\begin{array}{l}\text { NMD } \\
(\mathrm{n}=61)\end{array}$ & $\begin{array}{c}\text { Comparisons } \\
\text { between the } \\
3 \text { groups } \\
\text { p-value }\end{array}$ \\
\hline \multicolumn{5}{|l|}{ Motor developmental difficulties } \\
\hline $\begin{array}{l}\text { Parent-report delay and/or } \\
\text { abnormal motor development }\end{array}$ & $32(67 \%)^{a}$ & $16(27 \%)^{b}$ & $27(47 \%)^{a}$ & $<.001++* *$ \\
\hline $\begin{array}{l}\text { Associated developmental } \\
\text { coordination disorder }\end{array}$ & $30(67 \%)^{\mathrm{a}}$ & $14(22 \%)^{b}$ & $26(29 \%)^{a}$ & $<.001+\dagger * *$ \\
\hline \multicolumn{5}{|l|}{ Language developmental difficulties } \\
\hline $\begin{array}{l}\text { Parent-report delay and/or } \\
\text { abnormal language development }\end{array}$ & $20(40 \%)$ & $14(23 \%)$ & $20(35 \%)$ & $.124+\dagger$ \\
\hline $\begin{array}{l}\text { Associated communication/oral } \\
\text { language disorder }\end{array}$ & $15(31 \%)$ & $7(11 \%)$ & $12(21 \%)$ & $.05637+\dagger$ \\
\hline $\begin{array}{l}\text { Associated written language } \\
\text { disorder }\end{array}$ & $17(35 \%)^{a}$ & $6(10 \%)^{b}$ & $6(11 \%)^{b}$ & $.001 .002++* *$ \\
\hline \multicolumn{5}{|l|}{ Combined developmental difficulties } \\
\hline $\begin{array}{l}\text { Any motor or language disorders, } \\
\mathrm{n}(\%)\end{array}$ & $35(75 \%)^{a}$ & $18(29 \%)^{b}$ & $20(36 \%)^{b}$ & $<.001++* *$ \\
\hline $\begin{array}{l}\text { Two combined motor or language } \\
\text { disorders }{ }^{2}\end{array}$ & $15(33 \%)^{\mathrm{a}}$ & $5(8 \%)^{b}$ & $6(11 \%)^{b}$ & $.001 .005+\uparrow * *$ \\
\hline $\begin{array}{l}\text { Three combined motor or } \\
\text { language disorders }\end{array}$ & $6(13 \%)$ & $2(3 \%)$ & $4(7 \%)$ & $.128+t$ \\
\hline
\end{tabular}

\section{Note:}

+ Chi-2 test; $+\dagger$ Fisher exact test; ${ }^{*}$ indicates $p<.05$. ** indicates $p<.01{ }^{\mathrm{a}-\mathrm{b}}$ Means in a row without a common superscript letter differ $(p<.05)$.

${ }^{1}$ Statistical comparisons between each group (DMDD vs. MDD, and DMDD vs. NMD) are presented in the plain text.

${ }^{2}$ All subjects with communication/oral language disorder had reading difficulties. The difference between a mixed language disorder (oral + written) and the sequela of communication/oral language disorder on reading or writing abilities require further analyses not presented here. 
Table 3. Detailed motor difficulties in the subset of DMDD patients with in-depth motor assessments $(\mathrm{n}=29 / 53)$

\begin{tabular}{|c|c|}
\hline Tests & $\begin{array}{l}\text { Mean performance of DMDD youths } \\
\text { compared to standardized scores in } \\
\text { non-clinical population }{ }^{*}\end{array}$ \\
\hline \multicolumn{2}{|l|}{ Gross motor skills } \\
\hline MABC-2: Manual dexterity & $14^{\text {th }}$ percentiles, $95 \%$ CI $[13,15]^{* *}$ \\
\hline MABC-2: Aiming and Catching & $36^{\text {th }}$ percentiles, 95\% CI $[34,38]$ \\
\hline MABC-2: Balance & $27^{\text {th }}$ percentiles, $95 \%$ CI $[25,28]$ \\
\hline MABC-2 : total score & $18^{\text {th }}$ percentiles, 95\% CI $[16,20]$ \\
\hline \multicolumn{2}{|l|}{ Fine motor skills } \\
\hline EMG : Manual imitation & $-1.4 \mathrm{SD}, 95 \% \mathrm{CI}[-1.5,-1.3]^{* *}$ \\
\hline EMG : Digital imitation & $+0.1 \mathrm{SD}, 95 \%$ CI $[0.0,0.2]$ \\
\hline \multicolumn{2}{|l|}{ Visuo-spatial skills } \\
\hline DTVP-2: Motor-reduced visual perception quotient & $63^{\text {th }}$ percentiles, $95 \%$ CI $[61,65]$ \\
\hline DTVP-2: Visual-motor integration quotient & $48^{\text {th }}$ percentiles, $95 \%$ CI $[45,50]$ \\
\hline \multicolumn{2}{|l|}{ Graphism } \\
\hline BHK-ado, SD & $-1.8 \mathrm{SD}, 95 \% \mathrm{CI}[-2.0,-1.7]^{* *}$ \\
\hline
\end{tabular}

Note:

${ }^{*}$ Standardized scores in same-age non-clinical sample were provided by the manuals for each test. MABC-2: Movement Assessment Battery for Children 2nd edition (Henderson 2007), EMG: Manual and Digital Gnosopraxia Test (Vaivre-Douret 2011), DTVP-2: Developmental Test of Visual Perception 2nd edition (Hammill 1993), BHK-ado: Brief assessment of writing skill in adolescent (Charles 2003)

${ }^{* *}$ Scores in the problematic or pathologic ranges 
Table 4. Detailed language difficulties in the subset of DMDD patients with in-depth language assessments $(n=24 / 53)$

\begin{tabular}{|c|c|}
\hline Tests & $\begin{array}{c}\text { Mean performance of DMDD } \\
\text { youths compared to standardized } \\
\text { scores in non-clinical population }\end{array}$ \\
\hline \multicolumn{2}{|l|}{ Spoken language : phonology } \\
\hline EDA : Repetition logatom & $-0.3 \mathrm{SD}, 95 \% \mathrm{CI}[-0.5,-0.1]$ \\
\hline EDA : Suppression of the last phonem & $-1.4 \mathrm{SD}, 95 \% \mathrm{CI}[-1.6,-1.2]$ \\
\hline \multicolumn{2}{|l|}{ Spoken language : syntax and morphology } \\
\hline EDA : Syntax understanding & $-0.7 \mathrm{SD}, 95 \% \mathrm{CI}[-0.8,-0.6]$ \\
\hline \begin{tabular}{l|l} 
EDA : Sentence completion \\
\end{tabular} & - $1.0 \mathrm{SD}, 95 \%$ CI $[-1.3,-0.7]$ \\
\hline \multicolumn{2}{|l|}{ Spoken language : semantics } \\
\hline EDA : Lexical understanding & $69^{\text {th }}$ percentiles, $95 \%$ CI $[56,82]$ \\
\hline EDA : Picture designation & $40^{\text {th }}$ percentiles, $95 \%$ CI $[37,43]$ \\
\hline \begin{tabular}{l|l} 
PPVT : Picture denomination \\
\end{tabular} & $-2.0 \mathrm{SD}, 95 \% \mathrm{CI}[-2.3,-1.8]$ \\
\hline \multicolumn{2}{|l|}{ Written language : reading } \\
\hline Reading regular words & $-1.5 \mathrm{SD}, 95 \% \mathrm{CI}[-1.7,-1.3]$ \\
\hline Reading irregular words & $-2.0 \mathrm{SD}, 95 \% \mathrm{CI}[-2,3,-1.8]$ \\
\hline Reading pseudo-words & $-2.2 \mathrm{SD}, 95 \% \mathrm{CI}[-2.5,-2.0]$ \\
\hline \multicolumn{2}{|l|}{ Written language : writing } \\
\hline Dictation & $-1.4 \mathrm{SD}, 95 \% \mathrm{CI}[-1.6,-1.2]$ \\
\hline Text transcription & $-1.6 \mathrm{SD}, 95 \% \mathrm{CI}[-1.8,-1.4]$ \\
\hline
\end{tabular}

Note:

* Standardized scores in same-age non-clinical sample were provided by the manuals for each test. EDA (Billard 2012), PPVT: Peabody Picture Vocabulary Test (Dunn 2007), LMC-R (Khomsi 2003).

${ }^{* *}$ Scores in the problematic or pathologic ranges 
Table S1. Algorithm for the diagnosis of DMDD in the current study

\begin{tabular}{|c|c|}
\hline $\begin{array}{l}\text { Diagnostic } \\
\text { criteria: }\end{array}$ & Clinical description: \\
\hline A1 & $\begin{array}{l}\text { The temper outbursts are manifest verbally and/or behaviorally, such as in the form of } \\
\text { verbal rages, or physical aggression towards people or property }\end{array}$ \\
\hline $\mathrm{A} 2$ & $\begin{array}{l}\text { The reaction is grossly out of proportion in intensity or duration to the situation or } \\
\text { provocation. } \\
\text { and } \\
\text { The responses are inconsistent with developmental level. }\end{array}$ \\
\hline $\mathrm{B}$ & The temper outbursts occur, on average, three or more times per week \\
\hline $\mathrm{C} 1$ & $\begin{array}{l}\text { Nearly every day, the mood between temper outbursts is persistently negative (irritable, } \\
\text { angry, and/or sad). }\end{array}$ \\
\hline $\mathrm{C} 2$ & The negative mood is observable by others (e.g., parents, teachers, peers). \\
\hline $\mathrm{D}$ & $\begin{array}{l}\text { Criteria A-C have been present for at least } 12 \text { months. Throughout that time, the person } \\
\text { has never been without the symptoms of Criteria A-C for more than } 3 \text { months at a time. }\end{array}$ \\
\hline $\mathrm{E}$ & $\begin{array}{l}\text { The temper outbursts and/or negative mood are present in at least two settings (at home, at } \\
\text { school, or with peers) and must be severe in at least in one setting. }\end{array}$ \\
\hline $\mathrm{F}$ & Chronological age is at least 6 years (or equivalent developmental level). \\
\hline G & The onset is before age 10 years. \\
\hline $\mathrm{H}$ & $\begin{array}{l}\text { There has never been a distinct period lasting more than } 1 \text { day during which the full } \\
\text { symptom criteria, except duration, for a manic or hypomanic episode have been met. }\end{array}$ \\
\hline I & $\begin{array}{l}\text { The behaviors do not occur exclusively during the course of a Psychotic or Mood Disorder } \\
\text { (e.g., Major Depressive Disorder, Dysthymic Disorder, Bipolar Disorder) and are not } \\
\text { better accounted for by another mental disorder (e.g., Pervasive Developmental Disorder, } \\
\text { post-traumatic stress disorder, separation anxiety disorder) }\end{array}$ \\
\hline \multicolumn{2}{|r|}{ Diagnostic procedure: } \\
\hline \multicolumn{2}{|c|}{$\begin{array}{l}\text { A DMDD diagnosis was positively endorsed if the subjects presented at least eleven positive answers to } \\
\text { the diagnostic criteria described above. The final formulation for DMDD diagnostic criteria (1) are similar } \\
\text { to those developed for TDDD (34) except for two changes: }\end{array}$} \\
\hline (i) & $\begin{array}{l}\text { mood between the temper outbursts is persistently irritable or angry most of the day in } \\
\text { DD. In TDDD the item was endorsed positively if the mood was angry, irritable and/or sad. } \\
\text { ew exclusion criterion was introduced for DMDD 'The symptoms are not attributable to the } \\
\text { siological effects of a substance or to another medical or neurological condition'. }\end{array}$ \\
\hline
\end{tabular}


Table S2 Subgroups analyses to compare the rate of motor and language impairments in DMDD with and without associated ADHD

\begin{tabular}{|c|c|c|c|}
\hline & $\begin{array}{c}\text { DMDD/ } \\
\text { ADHD+ } \\
(n=22)\end{array}$ & $\begin{array}{l}\text { DMDD/ } \\
\text { ADHD- } \\
(n=31)\end{array}$ & $p$-value \\
\hline $\begin{array}{l}\text { Any developmental motor or language } \\
\text { disorders, } \mathrm{n}(\%)\end{array}$ & $18(86 \%)$ & $15(62 \%)$ & .013 \\
\hline Communication/oral language disorder & $9(41 \%)$ & $7(23 \%)$ & .152 \\
\hline Written language disorder & $8(36 \%)$ & $9(29 \%)$ & .573 \\
\hline Developmental coordination disorder & $14(63 \%)$ & $14(45 \%)$ & .184 \\
\hline Two combined motor or language disorders $*$ & $7(33 \%)$ & $7(29 \%)$ & .452 \\
\hline Three combined motor or language disorders & $4(19 \%)$ & $4(17 \%)$ & .597 \\
\hline
\end{tabular}

